\title{
ANÁLISE DA VISÃO DOS ACADÊMICOS CONCLUINTES DO CURSO DE CIÊNCIAS CONTÁBEIS - UNEMAT CAMPUS DE TANGARÁ DA SERRA NO ANO DE 2013/2, COM RELAÇÃO AO CURSO E A EXPECTATIVA DE INGRESSO NO MERCADO DE TRABALHO.
}

\author{
Cristiane Deutschmann ${ }^{1}$ \\ Josiane Silva Costa dos Santos ${ }^{2}$
}

\section{RESUMO}

Este estudo se propôs a avaliar a visão dos acadêmicos com relação ao curso de Ciências Contábeis da Universidade do Estado de Mato Grosso e traçar as preferências dos acadêmicos pelas áreas de atuação do campus de Tangará da Serra - MT, tendo como público alvo os acadêmicos concluintes no período de $2013 / 2$, cursando o $7^{\circ}$ e $8^{\circ}$ semestre. A coleta dos dados foi realizada com 50 acadêmicos matriculados no curso neste período, que corresponde a 79,37 \% do total matriculados, conforme as informações obtidas na Supervisão de apoio Acadêmico (SSA). O perfil dos entrevistados se caracterizou em sua maioria pelo sexo feminino, sendo analisada a visão com relação ao curso e demonstrar a expectativas e preferências de ingresso no mercado de trabalho. Através da pesquisa evidencia-se que os acadêmicos na sua maioria cursam o curso de Ciências Contábeis tendo em vista o ingresso no mercado de trabalho por meio de cargos administrativos e cargos públicos.

Palavras-chave: Curso de Ciências Contábeis, Contabilidade, Profissional Contábil.

\section{INTRODUÇÃO}

A contabilidade fornece informações necessárias para as tomadas de decisões, portanto, os contabilistas devem acompanhar a evolução que está em constantes modificações e que nos dias de hoje, ganharam velocidade com os avanços tecnológicos (COTRIN, SANTOS, JUNIOR, 2012).

A contabilidade dispõe de um leque vasto de oportunidades de trabalho, sendo exigido dos profissionais o conhecimento e até mesmo experiência prática em determinadas áreas (SCARPIN; ALMEIDA, 2010). A qualidade nos serviços contábeis se tornou relevante devido o aumento das exigências, visando sempre serviços de qualidade e eficiência. As empresas buscam profissionais competentes para auxilia-los e este diferencial possibilita uma carreira profissional de sucesso (GOMES, 2011).

A atuação do contador no mercado de trabalho é muito ampla, tendo como opção de emprego: autônomo, professor, auditor, órgãos públicos e dentre outros, porém as pessoas

\footnotetext{
1 Acadêmica do curso de Ciências Contábeis da UNEMAT - Campus de Tangará da Serra, e-mail: cristga27@hotmail.com

${ }^{2}$ Bacharel em Ciências Contábeis; Professora do curso de Ciências Contábeis da UNEMAT - Campus de Tangará da Serra, e-mail: josyane.costa@hotmail.com
} 
Análise da visão dos acadêmicos concluintes do curso de ciências contábeis - UNEMAT campus de Tangará da Serra no ano de 2013/2, com relação ao curso e a expectativa de ingresso no mercado de trabalho.

Cristiane Deutschmann

Josiane Silva Costa dos Santos

que conseguem destacar-se nesse mercado são aquelas que têm o diferencial que a profissão exige (OLIVEIRA, 2005).

De acordo com Rodrigues (2009) o mercado de trabalho exige que o profissional contábil esteja sempre se especializando, por meio de cursos de aperfeiçoamento, inteirar-se diariamente, de todas as novidades da área em que atua. A concorrência é um dos fatores preocupantes para o crescimento profissional, portanto os profissionais devem estar visando à qualidade, o atendimento e as inovações nos serviços prestados aos usuários.

O Curso de Ciências Contábeis iniciou suas atividades no dia 05 de março de 1.990, mantido pelo Centro de Ensino Superior de Tangará da Serra (CESUT) e ministrado pela Faculdade Ciências Contábeis e Administração de Tangará da Serra (FACCATS), lançando todos os anos novos profissionais contábeis no mercado de trabalho (UNEMAT, 2013).

Diante do exposto o problema da pesquisa concentra na seguinte questão: Qual a visão dos acadêmicos concluintes do curso de ciências contábeis, com relação ao curso e a expectativa de ingresso no mercado de trabalho?

O objetivo geral da pesquisa é analisar a visão dos concluintes do curso de Ciências Contábeis de Tangará da Serra- MT, com relação ao curso e a expectativa de ingresso no mercado de trabalho. Os objetivos específicos consistem em: avaliar a satisfação dos acadêmicos com relação ao curso de ciências contábeis e traçar as preferências dos acadêmicos pelas áreas de atuação.

\section{REFERENCIAL TEÓRICO}

\subsection{História da contabilidade}

A história da contabilidade iniciou-se com a necessidade de registros, onde o homem primitivo buscava técnicas para quantificar seu patrimônio, tendo assim o início dos registros de uma escrituração contábil, pois quantificava e evidenciava a riqueza patrimonial do indivíduo ou de sua família (SÁ, 2002).

De acordo com Andrade (2009), os registros contábeis iniciaram aproximadamente 4.000 a C., utilizado desde a decadência do Império Romano, aparecimento dos Bárbaros e do feudalismo, até aos dias de hoje. Entretanto, Sá (2007) ressalta que talvez antes da história das civilizações o homem primitivo teria inventado ferramentas e instrumentos de caça e 
Análise da visão dos acadêmicos concluintes do curso de ciências contábeis - UNEMAT campus de Tangará da Serra no ano de 2013/2, com relação ao curso e a expectativa de ingresso no mercado de trabalho.

Cristiane Deutschmann

Josiane Silva Costa dos Santos

pesca para contar seus rebanhos, portanto, já estava praticando uma das formas mais simples de contabilidade.

Segundo Martinelli (2002) a contabilidade evoluiu lentamente até o aparecimento da moeda. No período da troca de mercadorias, os comerciantes anotavam as obrigações, os direitos e os bens diante terceiros, porém, tratava-se de um inventário físico e sem avaliação monetária. Sá (2009) enfatiza que o aperfeiçoamento da contabilidade ao longo dos tempos, está ligado à necessidade de registros do comércio, assim surgiu à necessidade do homem acompanhar e controlar a evolução de seu patrimônio; controlar os bens que possuía, gastava ou devia, sempre em busca de descobrir uma maneira simples de aumentar seu capital.

A contabilidade passou a evoluir com o desenvolvimento cultural, social e econômico. No período do Renascimento Cultural, surgiu a figura do Frei Luca Bartolomeo de Pacioli, respeitado como um dos estudiosos da época, e que se consagrou como uma das maiores mentes de seu tempo, e tornou-se público como "pai da contabilidade" (COTRIN, SANTOS, JUNIOR, 2012).

Segundo Gomes (2011) pode-se identificar como marco histórico, o primeiro trabalho impresso sobre as partidas dobradas, escrito por Luca Pacioli, em fins de 1494, em Veneza na Itália. Considera-se esta fase como a pré-ciência.

A contabilidade no Brasil evoluiu de acordo com as necessidades comerciais. O primeiro contador a chegar ao Brasil foi Brás Cubas, cuja nomeação para o cargo de provedor da Fazenda Real e contador das Rendas e Direitos da Capitania em 23 de junho de 1551 (RIBEIRO, LOPES, PEDERNEIRAS, 2009).

A formação profissional de contador no Brasil iniciou-se com a aula de comércio no século XVIII e que no decorrer dos anos tornou-se à academia, que nos dias atuais se tornou Faculdade. A História da Contabilidade no Brasil foi pesquisada pelo professor Dr. Alberto Almada Rodrigues, que escreveu sua monografia sobre: "História da Profissão Contábil e das Instituições de Ensino de Ciência Contábil no Brasil até 1905”, que contêm datas importantes da história da contabilidade brasileira (SILVA, MARTINS, 2009).

Segundo Ribeiro, Lopes, Pederneiras (2009) a primeira legislação que constituiu o processo da escrituração contábil foi a Lei n 2.627, de 1940, que proporcionava critérios de avaliação das contas de ativo, receita, despesas, apuração dos lucros e perdas, distribuição de lucro e de reservas, constituindo assim, um marco legal de estabelecimento de procedimentos contábeis sistematizados no Brasil. 
Análise da visão dos acadêmicos concluintes do curso de ciências contábeis - UNEMAT campus de Tangará da Serra no ano de 2013/2, com relação ao curso e a expectativa de ingresso no mercado de trabalho.

Cristiane Deutschmann

Josiane Silva Costa dos Santos

\subsection{Profissional contábil}

A busca pela graduação em Ciências Contábeis inicia-se com o ingresso do estudante em um curso superior após a conclusão do ensino médio, o curso tem duração de quatro anos, abrangendo cerca de 3200 horas-aula. Para se obter o diploma de bacharel em contabilidade, com todos os direitos atribuídos à profissão os órgãos de classe impõem uma rígida bateria de exames. Após conquistar o diploma de nível superior, o Conselho Federal de Contabilidade (CFC) determina que o profissional seja submetido a realizar o exame de suficiência do conhecimento adquirido. Ao ser aprovado o bacharel estará habilitado para o exercício da profissão nas áreas de especialização (COTRIN; SANTOS; JUNIOR, 2012).

O profissional Contábil pode atuar como contador ou técnico em contabilidade conforme o Decreto Lei 9.295/46 trata :

da criação do Conselho Federal da Contabilidade e dos Conselhos Regionais de Contabilidade, definindo as atribuições do contador e do Técnico em contabilidade, dando-lhes competência, considerando as pessoas físicas ou jurídicas quando de seu registro no CRC, obrigando-os ao pagamento de anuidade fixada pelo respectivo conselho.

Segundo o Conselho Federal de Contabilidade - CFC decreto Lei 9.295/46 para ser um contador é exigido no mínimo à formação de bacharel em ciências contábeis e para exercer esta profissão com suas obrigações e responsabilidades é necessário ter seu registro profissional junto ao Conselho Regional de Contabilidade. Para ser técnico em contabilidade desempenhar suas funções é necessário o diploma em curso de segundo grau em técnico de contabilidade.

Em 11 de junho de 2010, a lei nº 12.249/10 alterou o Decreto Lei 9295/46, apresentando modificações nas obrigações do contador, como o exame de suficiência, que passou a ser obrigatório para o Profissional contábil solicitar seu registro junto ao Conselho Regional da Contabilidade. Alterar-se para o técnico em Contabilidade o período para poder habilitar-se junto ao CRC, sendo que não será concedido registro para estes profissionais após junho de 2015.

De acordo com CFC (2013), no Brasil há 164.544 profissionais registrados e ativos, o estado do Mato Grosso possui 7.581 contadores e 2.298 técnicos em contabilidade totalizando 9.879 profissionais ativos, que correspondente à 2,03\% dos profissionais registrados no Brasil. 
Análise da visão dos acadêmicos concluintes do curso de ciências contábeis - UNEMAT campus de Tangará da Serra no ano de 2013/2, com relação ao curso e a expectativa de ingresso no mercado de trabalho.

Cristiane Deutschmann Josiane Silva Costa dos Santos

Para os profissionais que almejam atuar na área de auditoria de empresas abertas ou instituições financeiras a Comissão de Valores Mobiliários (CVM) exige que sejam realizados exames adicionais de conhecimento específico, que são instituídos pelo CFC. Não é exigido estágio prático profissional anterior em empresa de auditoria independente ou instituição financeira (COTRIN, SANTOS, JUNIOR, 2012).

No mercado de trabalho das grandes empresas é altamente valorizada a capacidade de se antecipar aos riscos; planejamento estratégico; atitude proativa; alta capacidade para se comunicar de forma oral e escrita; altos padrões morais e éticos; visão de longo prazo; capacidade empreendedora; e a intenção de sempre dar continuidade a sua formação profissional (PENNA, 2008).

De acordo com Pereira e Xavier (2000, apud SANTOS 2007), alguns dos grandes desafios do contador atual são: deixar de lado a ideia da contabilidade tradicional; ter informações sobre a organização de maneira global; utilizar essas informações de modo que sejam úteis aos gestores; cultivar um canal de comunicação eficaz entre os usuários da informação contábil e tornar-se indispensável à organização.

Com o novo mercado de trabalho à qualificação de um profissional está relacionada com as suas habilidades e competências que por muitas vezes não está diretamente contidas ao seu currículo ou a sua formação acadêmica. Assim, a formação do profissional contábil sofre alterações, devido à "ingresso de inovações e reorganização dos próprios processos de trabalho inerentes à contabilidade (DEITOS, 2008).

Segundo Deitos (2008) o novo contador não deve de forma alguma manter-se alienado a contabilidade exclusivamente, mas deve deter um amplo conhecimento de áreas afins, tais como legislação, administração, economia, etc., $\mathrm{O}$ conhecimento de outras áreas deve ser passível de ser aplicado na resolução criativa de problemas da área da contabilidade.

\subsection{Código de ética profissional contábil}

De acordo com o CFC (2006) o Código de Ética do profissional Contábil contém 6 capítulos, divididos em: objetivos; deveres e Proibições; Valores dos Serviços Profissionais; Deveres em Relação aos Colegas e á Classe; as Penalidades e das Disposições Gerais.

Segundo o CFC (2006) o contabilista tem como dever, exercer a profissão com zelo, diligência e honestidade, analisando a legislação vigente e protegendo os interesses de seus 
Análise da visão dos acadêmicos concluintes do curso de ciências contábeis - UNEMAT campus de Tangará da Serra no ano de 2013/2, com relação ao curso e a expectativa de ingresso no mercado de trabalho.

Cristiane Deutschmann

Josiane Silva Costa dos Santos

clientes e empregadores, sem prejuízo da dignidade e independência profissionais; guardar sigilo em razão do exercício profissional; zelar pela sua competência exclusiva na orientação técnica dos serviços; certificar-se de todas as situações, antes de informar sua opinião sobre fato; manifestar a qualquer tempo a existência de impedimento para o exercício da profissão.

Segundo Fortes (2002) O Código de ética profissional do Contabilista é utilizado como uma fonte orientadora da conduta dos profissionais da classe contábil brasileira, que tem como objetivo fixar a forma pela qual se devem conduzir os profissionais da contabilidade, principalmente no exercício das suas atividades e prerrogativas profissionais instituídas na legislação vigente.

Sá (2009) enfatiza que a ética profissional é parte da ética. É ter consciência de cumprir com o seu dever da forma correta possível. A profissão é um meio de suprir as necessidades humanas relacionadas ao trabalho.

O profissional ético deve ser tecnicamente e moralmente preparado para exercer uma função dentro de uma organização ou de forma autônoma. O profissional técnico que diz possuir as habilidades necessárias e na realidade não está preparado prejudica a si próprio e à empresa que o contratou e moralmente, porque o caráter ético é notado em muitos por menores de seu desempenho (ARRUDA, 2003).

O contador deve apreender com profundidade a contabilidade, os Princípios e as Normas Contábeis, o Código de Ética e as diversas legislações, conforme descrito no Código Civil. Ao valorizar sua profissão saberá de seu valor e aplicar os princípios éticos, não como uma obrigação legal ou organizacional, mas como instrumento fundamental de conduta, condição que na qual sua existência profissional perde o sentido. Assim provará sua importância e relevância para a sociedade, não apenas pela profissão que desempenha, mas também pelo exemplo de profissionalismo e de conduta ética e moral (DOMINGUES; SILVA, 2007).

\section{METODOLOGIA}

$\mathrm{Na}$ realização deste trabalho, utilizou-se a pesquisa exploratória caracterizada pelo método quantitativo, tendo como base o artigo de Araújo (2008) e Scarpin (2010).

A pesquisa exploratória se caracteriza quando há pouco conhecimento sobre o tema escolhido e torna-se difícil formular hipóteses precisas, busca-se conhecer com maior profundidade e torna-lo mais claro. Para que o estudo seja considerado exploratório, deverá 
Análise da visão dos acadêmicos concluintes do curso de ciências contábeis - UNEMAT campus de Tangará da Serra no ano de 2013/2, com relação ao curso e a expectativa de ingresso no mercado de trabalho.

Cristiane Deutschmann

Josiane Silva Costa dos Santos

concentrar-se em algo que necessita ser esclarecido ou explorado nesse campo de conhecimento (BEUREN et al, 2004).

O método de pesquisa quantitativa é bem utilizado no desenvolvimento de investigações descritivas, procuram descobrir e classificar a relação entre as variáveis, buscando sempre a causa e o efeito. O termo quantitativo através da coleta de informações significa quantificar as opiniões e os dados, sendo muito utilizada no desenvolvimento de pesquisas no âmbito social, comunicação, de opinião, econômico e de administração (SILVA, 2010).

A coleta de dados foi realizada através de questionários que se refere à técnica de pesquisa mais utilizada, formada de perguntas relacionadas e ordenadas com foco no tema central, que são respondidas pelo público alvo. A partir dos dados obtidos é possível mensurar cada resposta, unindo a opinião de vários entrevistados (OLIVEIRA, et al.,2003).

O questionário aplicado contou com 13 questões sendo aplicado ao publico alvo no período de Setembro de 2013, elaborado de modo que através das respostas conseguiu-se analisar a visão dos concluintes do curso de Ciências Contábeis de Tangará da Serra- MT, com relação ao curso e ao mercado de trabalho.

O estudo foi realizado no campus da UNEMAT de Tangará da Serra/MT, tendo atualmente 243 acadêmicos matriculados entre o $1^{\circ}$ ao $8^{\circ}$ semestre, a pesquisa foi delimitada aos acadêmicos concluintes no período de $2013 / 2$, cursando o $7^{\circ}$ e $8^{\circ}$ semestre, a escolha foi realizada por ser o último ano de conclusão do curso, contendo o número de 63 acadêmicos matriculados e contamos com a colaboração de 50 acadêmicos entrevistados conforme a supervisão de apoio acadêmico (SAA).

\section{DISCUSSÃO DE RESULTADOS}

A discussão dos resultados buscou traçar o perfil dos entrevistados, identificar os motivos que levaram a escolha do curso e se quando optou pelo curso buscou conhecer a grade curricular, foi solicitada uma avaliação dentre os critérios básicos de estrutura para ministrar o curso e avaliação de algumas disciplinas que está relacionada às praticas contábeis e voltadas para o mercado de trabalho. De acordo com os dados, possibilita avaliar a satisfação dos acadêmicos com relação ao curso de Ciências Contábeis.

Foram Questionados alguns critérios relacionados às expectativas dos acadêmicos, tais como: A visão e o conhecimento ao longo dos semestres mudaram a sua opinião sobre o 
Análise da visão dos acadêmicos concluintes do curso de ciências contábeis - UNEMAT campus de Tangará da Serra no ano de 2013/2, com relação ao curso e a expectativa de ingresso no mercado de trabalho.

Cristiane Deutschmann

Josiane Silva Costa dos Santos

curso; no decorrer do curso, buscou-se aperfeiçoar através de cursos profissionalizantes fora da Universidade; após a conclusão do curso, tem interesse de fazer uma pós-graduação; está trabalhando no momento; a área que atua está relacionada ao curso de Ciências Contábeis e se surgiram oportunidades de trabalho na área ao estar cursando o curso. Além disso, foi solicitado o tempo de atuação na área contábil e qual a área que pretende atuar ou se especializar. Os dados, permitem identificar e traçar as preferências dos acadêmicos pelas áreas de atuação.

Diante dos dados coletados através dos entrevistados, buscou-se identificar o perfil dos acadêmicos quanto o sexo e a faixa etária, conforme a tabela 1 .

Tabela 1 - Perfil dos entrevistados

\begin{tabular}{cc|c}
\hline \multicolumn{2}{|c|}{ Sexo } & \multicolumn{2}{c}{ Faixa etária } \\
\hline Feminino $60 \%$ & 16 a 20 anos & $4 \%$ \\
\hline Masculino $40 \%$ & 21 a 25 anos & $54 \%$ \\
\hline & & 26 a 30 anos $\quad 32 \%$ \\
\hline & Acima de 31 anos $10 \%$ \\
\hline
\end{tabular}

Fonte: Dados da pesquisa

Na tabela 1 há evidência que sexo feminino obtém o maior índice com $60 \%$ do total dos acadêmicos matriculados contém $40 \%$ do sexo masculino, este resultado foi obtido da pesquisa de Sauberlich (2012) que foi realizada na cidade de Tangará da Serra - MT no campus da Unemat no período de janeiro a março de 2012 com o tema: fatores que produzem evasão acadêmica no curso de ciências contábeis da Unemat de Tangará da Serra/MT. Onde demonstrou que o sexo feminino obteve $66 \%$ e o sexo masculino $34 \%$, nota-se que as mulheres cada vez mais estão buscando se profissionalizar para disputar vagas no mercado de trabalho.

Com relação à faixa etária dos acadêmicos que estão concluindo o curso, o maior percentual da faixa está concentrada entre 21 a 25 anos com $54 \%$ e o menor percentual entre 16 a 20 anos com $4 \%$, observa-se que a faixa de 26 a 30 anos obteve $32 \%$, pode se analisar que os alunos após a formação do ensino médio não buscou a formação acadêmica e devido às exigências do mercado de trabalho estão buscando se profissionalizar para ocupar seu espaço no mercado.

A escolha pelo curso de Ciências Contábeis pode ser influenciada por diversos fatores, como demonstra na tabela 2, onde foi questionado qual o motivo pela escolha do curso de ciências contábeis. 
Análise da visão dos acadêmicos concluintes do curso de ciências contábeis - UNEMAT campus de Tangará da Serra no ano de 2013/2, com relação ao curso e a expectativa de ingresso no mercado de trabalho.

Cristiane Deutschmann

Josiane Silva Costa dos Santos

Tabela 2 - Motivos pela escolha do curso de Ciências Contábeis, segundo os entrevistados.

\begin{tabular}{c|c}
\hline Critérios & \% \\
\hline Falta de opção & 38 \\
\hline Visão de Sucesso Profissional & 26 \\
\hline Tem experiência ou trabalha na área & 14 \\
\hline Gosta de matemática & 10 \\
\hline Influência ou conhecido que atua na área & 8 \\
\hline Outros & 4 \\
\hline
\end{tabular}

Fonte: Dados da pesquisa

Observa-se que o principal fator foi à falta de opção com $38 \%$ evidenciando um indicador preocupante com relação ao mercado de trabalho, porém nota-se que com $26 \%$ dos acadêmicos tem visão que o curso proporciona sucesso profissional, para aqueles que se dedicam e se mantém antenados com a mudança da globalização.

O trabalho de Preis et al (2013) foi realizado na região do Vale do Ribeira em São Paulo tendo como tema: $\mathrm{O}$ ensino em contabilidade: Uma análise do perfil dos estudantes do curso de ciências contábeis quanto à sua percepção do mercado de trabalho e o seu grau de capacitação, onde obteve resultados diferentes, tendo o maior índice com 47,72\% com os outros motivos e na pesquisa realizada em Tangará da Serra Mato Grosso, obtivemos apenas 4\%. O segundo índice com 20,45\% a motivação dos pais ou outras pessoas e em Tangará da Serra obtivemos o índice de $8 \%$ com a influência ou conhecido que atua na área. O terceiro índice com $15,90 \%$ a falta de opção e em nossa região obteve o índice de $38 \%$. Portanto, pode-se analisar que os motivos que influência na escolha do curso, pode variar conforme a economia e o mercado de trabalho entre São Paulo e Mato Grosso.

Verifica-se que o motivo da escolha do curso de ciências contábeis em Tangará da Serra - MT ocorre pela falta de opção, pois os alunos concluem o ensino médio e provavelmente não buscam orientação dentre as opções disponíveis em Tangará da Serra.

$\mathrm{Na}$ pesquisa foi questionado se os acadêmicos conheciam a grade curricular quando optaram pelo curso, os dados revelou que $78 \%$ dos acadêmicos que optou pelo curso de Ciências Contábeis não buscou conhecer a grade curricular e apenas $22 \%$ dos acadêmicos obteve o conhecimento da grade antes de iniciar o curso, pode concluir que a falta de opção pela escolha no curso influência no desinteresse de conhecer a grade curricular.

$\mathrm{Na}$ tabela 4 foi solicitado aos acadêmicos para analisar o curso de Ciências Contábeis utilizando os critérios ruim, regular ou ótimo. 
Análise da visão dos acadêmicos concluintes do curso de ciências contábeis - UNEMAT campus de Tangará da Serra no ano de 2013/2, com relação ao curso e a expectativa de ingresso no mercado de trabalho.

Cristiane Deutschmann

Josiane Silva Costa dos Santos

Tabela 4 - Dentre as opções abaixo, analise com relação ao Curso de Ciências Contábeis, seguindo os critérios relacionados.

\begin{tabular}{l|c|c|c}
\multicolumn{1}{c|}{ Critérios } & Ruim & Regular & Ótimo \\
\hline Departamento de Ciências Contábeis & $14 \%$ & $78 \%$ & $8 \%$ \\
\hline Estrutura física da Universidade & $24 \%$ & $70 \%$ & $8 \%$ \\
\hline Grade curricular & $14 \%$ & $80 \%$ & $8 \%$ \\
\hline Professores & $2 \%$ & $76 \%$ & $22 \%$ \\
\hline Eventos/ Cursos/ Palestra & $58 \%$ & $34 \%$ & $8 \%$ \\
\hline Laboratório de Informática & $60 \%$ & $36 \%$ & $4 \%$ \\
\hline Biblioteca & $14 \%$ & $56 \%$ & $30 \%$ \\
\hline Banheiros & $52 \%$ & $38 \%$ & $10 \%$ \\
\hline Cantina & $28 \%$ & $54 \%$ & $18 \%$ \\
\hline
\end{tabular}

Fonte: Dados da pesquisa

Os critérios utilizados na pesquisa como demonstra na tabela 4, foram escolhidos devido ser critérios básicos de estrutura para desempenhar e ministrar cursos superiores de graduação.

Perante as informações obtidas na tabela 4 , foi possível identificar e verificar que os acadêmicos estão insatisfeitos com o Curso de Ciências Contábeis, dentre a análise, verificase que o critério Ruim obteve 3 indicadores superior com relação aos demais, sendo em primeiro lugar o laboratório de Informática com 60\%; em segundo lugar os Eventos, Cursos e Palestras com 58\% e o terceiro lugar os banheiros com 52\%. No critério Regular obteve 6 indicadores superiores, destacando-se em primeiro lugar a grade curricular com 80\%; em segundo lugar o departamento de Ciências Contábeis com $78 \%$ e em terceiro lugar os professores com $76 \%$. Nota-se que o critério ótimo não obteve nenhum índice superior aos outros indicadores, em primeiro lugar com $30 \%$ a biblioteca; em segundo lugar com $22 \%$ os professores e em terceiro lugar com $18 \%$ a cantina.

A tabela 5 evidência a insatisfação com relação algumas disciplinas e com a SECIC Semana de Ciências Contábeis, influenciando na qualidade do ensino.

Tabela 5 - Conforme opinião, análise os critérios relacionados a baixo e atribua uma nota de 0 a 5 :

\begin{tabular}{l|c|c|c|c|c|c}
\hline \multicolumn{1}{c|}{ Critérios } & Nota 0 & Nota 1 & Nota 2 & Nota 3 & Nota 4 & Nota 5 \\
\hline TCC & $10 \%$ & $12 \%$ & $20 \%$ & $28 \%$ & $20 \%$ & $10 \%$ \\
\hline Estágio supervisionado & $48 \%$ & $18 \%$ & $16 \%$ & $12 \%$ & $6 \%$ & $0 \%$ \\
\hline Aula de laboratório & $16 \%$ & $18 \%$ & $32 \%$ & $22 \%$ & $10 \%$ & $2 \%$ \\
\hline SECIC & $10 \%$ & $10 \%$ & $20 \%$ & $18 \%$ & $20 \%$ & $22 \%$ \\
\hline Jogos de Empresas & $46 \%$ & $18 \%$ & $6 \%$ & $14 \%$ & $10 \%$ & $6 \%$ \\
\hline
\end{tabular}

Fonte: Dados da pesquisa 
Análise da visão dos acadêmicos concluintes do curso de ciências contábeis - UNEMAT campus de Tangará da Serra no ano de 2013/2, com relação ao curso e a expectativa de ingresso no mercado de trabalho.

Cristiane Deutschmann

Josiane Silva Costa dos Santos

Os critérios utilizados na pesquisa como TCC, Estágio supervisionado e a aula de laboratório foram escolhidos por estarem ligado diretamente às práticas contábeis e a SECIC e os jogos de empresas por estarem voltados para o mercado de trabalho.

Nota-se na tabela 5 que os acadêmicos estão insatisfeitos com 2 disciplinas, obtendo a nota 0 com $48 \%$ o estágio supervisionado e com $46 \%$ os jogos de empresas, a aula de laboratório obteve a nota 2 com 32\%, o TCC (Trabalho de conclusão de curso) obteve a nota 3 com 28\%, e a SECIC (Semana Ciências Contábeis) obteve a nota 5 com $22 \%$.

O estágio supervisionado e Jogos de empresas são disciplinas de suma importância para o conhecimento prático da contabilidade, nota-se que conforme demonstrado na tabela 5, o departamento de Ciências Contábeis deve rever a metodologia aplicada nas disciplinas e que consequentemente, irá influenciar na qualidade da formação dos acadêmicos e no ingresso no mercado de trabalho.

Diante dos dados anteriores, a tabela 6 irá demonstrar as expectativas dos acadêmicos.

Tabela 6 - Critérios das expectativas dos acadêmicos.

\begin{tabular}{|c|l|c|c|}
\hline Sequência & \multicolumn{1}{|c|}{ Descrição } & Sim & Não \\
\hline $1^{\text {o }}$ & $\begin{array}{l}\text { A visão e o conhecimento ao longo dos semestres mudaram a } \\
\text { sua opinião sobre o curso? }\end{array}$ & $90 \%$ & $10 \%$ \\
\hline $2^{\circ}$ & $\begin{array}{l}\text { No decorrer do curso, buscou-se aperfeiçoar através de cursos } \\
\text { profissionalizantes fora da Universidade? }\end{array}$ & $62 \%$ & $38 \%$ \\
\hline $3^{\circ}$ & $\begin{array}{l}\text { Após a conclusão do curso, tem interesse de fazer uma pós- } \\
\text { graduação? }\end{array}$ & $86 \%$ & $14 \%$ \\
\hline $4^{\text {o }}$ & Está trabalhando no momento? & $84 \%$ & $16 \%$ \\
\hline $5^{\circ}$ & $\begin{array}{l}\text { A área que você atua está relacionada ao curso de Ciências } \\
\text { Contábeis? }\end{array}$ & $50 \%$ & $50 \%$ \\
\hline $6^{\circ}$ & $\begin{array}{l}\text { Surgiram oportunidades de trabalho na área ao estar cursando } \\
\text { o curso? }\end{array}$ & $34 \%$ & $66 \%$ \\
\hline
\end{tabular}

Fonte: Dados da pesquisa.

No primeiro item da tabela 6 , foi questionado sobre a visão e o conhecimento ao longo dos semestres mudou a opinião sobre o curso, houve evidencias de um índice alto com 90\% dos acadêmicos que mudou a visão e o conhecimento no decorrer do curso e apenas $10 \%$ não mudaram. Este índice vai de encontro ou condiz com a resposta da tabela 3, pois os acadêmicos em sua maioria reconhecem não conhecer a grade do curso antes de iniciar o curso. 
Análise da visão dos acadêmicos concluintes do curso de ciências contábeis - UNEMAT campus de Tangará da Serra no ano de 2013/2, com relação ao curso e a expectativa de ingresso no mercado de trabalho.

Cristiane Deutschmann

Josiane Silva Costa dos Santos

O curso de Ciências Contábeis proporciona um leque grande de oportunidades em diversas áreas, porém os acadêmicos devem buscar se aperfeiçoar e se profissionalizar para manter-se atualizado com os avanços da contabilidade.

O segundo item questionou se no decorrer do curso, buscou-se aperfeiçoar através de cursos profissionalizantes fora da Universidade, nota-se que com $62 \%$ dos acadêmicos estão buscando se profissionalizar fora da Universidade e com $38 \%$ não buscou, porém, deve levar em consideração os acadêmicos que optou pelo curso e não pretende atuar na área. Porém o Curso de Ciências Contábeis exige que todos os acadêmicos realizem atividades complementares e apresentem os certificados para realizar a colação de grau e no Art. $2^{\circ}$ dos deveres do código de ética do profissional da contabilidade, ressalta que deve se cumprir os programas obrigatórios de educação Continuada pelo Conselho Federal de Contabilidade.

No terceiro item foi questionado se após a conclusão do curso, tem interesse de fazer uma pós-graduação para se especializar em uma área especifica da contabilidade, $86 \%$ dos acadêmicos pretender fazer uma pós-graduação após a conclusão do curso e apenas $14 \%$ não tem interesse. Atualmente as pós Graduações na cidade de Tangará da Serra são ministradas por faculdades particulares, índice esse que poderia ser mais expressivo com pós Graduações gratuitas no Campus da Unemat, onde atenderia a cidade e a região. Segundo os dados extraídos do site da UNEMAT, o último curso de especialização ministrado no polo de Tangará da Serra - MT iniciou em 2007 e finalizou em 2008 tendo foco em finanças, controladoria e auditoria.

No quarto item identifica-se que $84 \%$ dos acadêmicos estão trabalhando no momento e apenas 16\% dos acadêmicos estão desempregados. Na pesquisa de Sauberlich (2012) demonstra que $78 \%$ dos acadêmicos que iniciou o curso estavam trabalhando e apenas $22 \%$ estão desempregados, nota-se que esse índice pode influenciar na escolha do curso, por ser ministrado no período noturno.

No quinto item evidencia que 50\% dos acadêmicos estão atuando na área relacionada à contabilidade e 50\% atua em outras áreas, nota-se um índice alto de acadêmicos que não estão atuando na área que pretende ou deseja atuar, na tabela 8 demonstra as preferências de atuação dos acadêmicos.

A economia em Tangará da Serra destaca-se com um índice elevado de 56,6\% da prestação de serviços segundo o perfil socioeconômico (2011), no âmbito geral a cidade de Tangará da Serra - MT dispõem de diversas faculdades e lançam por ano vários profissionais 
Análise da visão dos acadêmicos concluintes do curso de ciências contábeis - UNEMAT campus de Tangará da Serra no ano de 2013/2, com relação ao curso e a expectativa de ingresso no mercado de trabalho.

Cristiane Deutschmann

Josiane Silva Costa dos Santos

na área, mediante a esta informação foi questionado aos acadêmicos se no decorrer do curso surgiram oportunidades de trabalho como demonstra no sexto item da tabela 6. Nota-se um índice elevado de $66 \%$ que não teve oportunidades de trabalho e justifica-se pela falta de experiência dos acadêmicos e por excesso de mão de obra e 34\% tiveram oportunidades na área contábil, índice esse que pode ser analisado pelo diferencial de cada acadêmico e por se destacar no mercado.

No entanto, o mercado busca profissionais que tenha experiência e capacitação na área, na tabela 7 demonstra o nível de experiência através do tempo de atuação na área contábil dos acadêmicos.

Tabela 7 - Qual o tempo de atuação na área contábil.

\begin{tabular}{c|c}
\hline Critérios & $\%$ \\
\hline 1 a 6 meses & $2 \%$ \\
\hline 7 meses até 1 ano & $6 \%$ \\
\hline 1 a 2 anos & $14 \%$ \\
\hline 3 a 5 anos & $20 \%$ \\
\hline Não atua & $58 \%$ \\
\hline
\end{tabular}

Fonte: Dados da pesquisa.

Levantou-se um índice de 58\% dos acadêmicos que não atuam na área contábil, destacase em segundo lugar com índice de $20 \%$ acadêmicos que estão atuando na área entre 3 a 5 anos e $14 \%$ atuam entre 1 a 2 anos.

O profissional contábil pode atuar em diversas áreas, mediante o leque de oportunidade extenso, pretende-se traçar as preferências dos acadêmicos quanto seu ingresso no mercado de trabalho e as áreas mais almejadas. Conforme demonstra na tabela 8.

Tabela 8 - Qual área pretende atuar/ especializar? Assinale apenas duas alternativas considerando os critérios, sendo 1 para a primeira opção e 2 para a segunda opção:

\begin{tabular}{c|c|c}
\hline Critérios & $\mathbf{1}^{\mathbf{o}}$ opção & $\mathbf{2}^{\mathbf{o}}$ opção \\
\hline Cargos públicos & $48 \%$ & $18 \%$ \\
\hline Cargos Administrativos & $20 \%$ & $30 \%$ \\
\hline Contador & $12 \%$ & $8 \%$ \\
\hline Professor & $6 \%$ & $8 \%$ \\
\hline Financeiro & $6 \%$ & $4 \%$ \\
\hline Auditor & $6 \%$ & $14 \%$ \\
\hline Perito Contábil & $2 \%$ & $14 \%$ \\
\hline Não quer atuar na área & $0 \%$ & $4 \%$ \\
\hline
\end{tabular}

Destacou-se com $48 \%$ os cargos público sendo a primeira opção e com $30 \%$ os cargos administrativos sendo a segunda opção, dados estes que estão relacionados com a tabela 3, onde demostra que os acadêmicos optou pelo curso por falta de opção e com o decorrer do 
Análise da visão dos acadêmicos concluintes do curso de ciências contábeis - UNEMAT campus de Tangará da Serra no ano de 2013/2, com relação ao curso e a expectativa de ingresso no mercado de trabalho.

Cristiane Deutschmann

Josiane Silva Costa dos Santos

curso não pretende atuar na área e consequentemente concluem o curso de Ciências Contábeis visando prestar concursos publico e cargos administrativos como demonstra na tabela 8 .

Nota-se no trabalho de Araújo e Santana (2008) realizado em Brasília tendo como tema: Análise das percepções e expectativas dos alunos de ciências contábeis na universidade de Brasília quanto ao perfil do professor e inserção no mercado de trabalho, que obteve $69,1 \%$ dos acadêmicos pretende atuar em cargos públicos, por proporcionar estabilidade profissional e segurança financeira, porém é uma das áreas mais concorridas e que exige mais esforços e dedicação.

\section{CONSIDERAÇÕES FINAIS}

Com base nos dados obtidos foi possível responder aos objetivos propostos conforme a pesquisa. Diante do objetivo geral onde pretende-se analisar a visão dos concluintes do curso de Ciências Contábeis de Tangará da Serra- MT, com relação ao curso e a expectativa de ingresso no mercado de trabalho, a pesquisa permitiu identificar que a maioria dos acadêmicos opta pelo curso de ciências contábeis por falta de opção e não buscam conhecer a grade curricular e que no decorrer do curso, através do conhecimento adquirido modificou sua opinião, que irá influenciar diretamente na qualificação para o mercado de trabalho e na escolha da área de atuação.

O primeiro objetivo específico constituiu em avaliar a visão dos acadêmicos com relação ao curso, evidenciou na pesquisa que dentre os critérios básicos de estrutura os acadêmicos estão insatisfeitos, tendo percentuais altos nos principais itens, tais como: o laboratório de informática, os eventos e palestra que o departamento proporciona aos acadêmicos e os banheiros.

O estágio Supervisionado e os jogos de empresas são disciplinas que estão relacionadas às práticas contábeis e voltadas para o mercado de trabalho, os acadêmicos estão insatisfeito por proporcionar conhecimento superficial, o estágio supervisionado pode ser justificado por não ter orientação em sala de aula e por outro lado a disciplina de jogos de empresas é ministrada em sala, ressaltando ainda que fossem realizados em escritórios e em empresas poderia agregar maior conhecimento na prática, possibilitando facilidade no ingresso ao mercado de trabalho. 
Análise da visão dos acadêmicos concluintes do curso de ciências contábeis - UNEMAT campus de Tangará da Serra no ano de 2013/2, com relação ao curso e a expectativa de ingresso no mercado de trabalho.

Cristiane Deutschmann

Josiane Silva Costa dos Santos

O segundo objetivo pretende-se traçar as preferências dos acadêmicos pelas áreas de atuação, mediante a pesquisa identifica a $1^{\circ}$ opção como $48 \%$ os cargos públicos e a $2^{\circ}$ opção com $30 \%$ os cargos administrativos. Portanto, nota-se que a escolha por atuar em cargos públicos não abrange apenas a cidade de Tangará da Serra e região e sim ao nível de Brasil, por proporcionar estabilidade profissional e segurança financeira.

Sugere-se ao departamento de Ciências Contábeis da Unemat Campus de Tangara da Serra - MT reavalie a estrutura física e básica para realização das aulas; realizar um trabalho em parceria com as escolas do município com relação à orientação e incentivos pela escolha do curso; exigir que os professores ministrem aulas práticas para proporcionar conhecimento e entendimento dos processos na prática fora da Universidade; oferecer cursos gratuitos de pós Graduação no Campus.

Sugere-se aos acadêmicos futuras pesquisas tais como: Analise dos cursos oferecidos de pós-graduações na Cidade de Tangará da serra - MT; avaliar o curso de Ciências Contábeis da Unemat através de comparação com as outras instituições.

O estudo teve como limitação o $7^{\circ}$ e o $8^{\circ}$ semestre devido os acadêmicos estarem concluindo o curso, vale ressaltar que à disciplina trabalho de conclusão de curso (TCC) iniciar no $7^{\circ}$ e $8^{\circ}$ semestre o que impossibilita fazer o acompanhamento desde o inicio do curso, onde proporcionaria obter dados mais completos.

\section{REFERÊNCIAS BIBLIOGRAFICAS}

ANDRADE, Álvaro P. "Origem e Evolução Histórica da Contabilidade". In: RIBEIRO FILHO, José F.; LOPES, Jorge; PEDERNEIRAS (Org), Marcleide. Estudando Teoria da Contabilidade. São Paulo: Atlas: 2009.

ARAUJO, M. D. C., SANTANA, C. M. (2008). Análise das percepções e expectativas dos alunos de ciências contábeis na universidade de Brasília quanto ao perfil do professor e inserção no mercado de trabalho. Anais do Congresso USP de Contabilidade e Controladoria, São Paulo, Brasil, 8.

ARRUDA, Maria Cecília Coutinho de. Fundamentos de Ética Empresarial e Econômica. 2.ed. São Paulo: Atlas, 2003.

BEUREN, Ilse Maria et al. Como elaborar trabalhos em contabilidade. 2. Ed. - São Paulo: Atlas, 2004.

CONSELHO FEDERAL DE CONTABILIDDADE. Legislação da profissão contábil. $2^{\mathrm{a}}$ edição. Brasília: CFC, 2006. Disponível em: <http://www.estruturalcontabilidade.com.br/wp- 
Análise da visão dos acadêmicos concluintes do curso de ciências contábeis - UNEMAT campus de Tangará da Serra no ano de 2013/2, com relação ao curso e a expectativa de ingresso no mercado de trabalho.

Cristiane Deutschmann

Josiane Silva Costa dos Santos

content/plugins/downloads-manager/upload/legislacao_2006.pdf>. Acesso 29 de Jun. de 2013.

CONSELHO FEDERAL DE CONTABILIDDADE. Disponível em:

<http://www.portalcfc.org.br/legislacao/decretos/> . Acesso 29 de Jun. de 2013.

CONSELHO FEDERAL DE CONTABILIDDADE. Disponível em:

$<$ http://www3.cfc.org.br/spw/crcs/ConselhoRegionalAtivo.aspx>. Acesso 29 de Jun. de 2013.

COTRIN, Anderson Meira; SANTOS, Aroldo Luiz; JUNIOR, Laerte Zotte. A evolução da contabilidade e o mercado de trabalho para o contabilista. Revista Conteúdo, Capivari, v.2, n.1, jan./jul. 2012. Disponível em:

$<$ http://www.conteudo.org.br/index.php/conteudo/article/viewArticle/70>. Acesso 05 Out. de 2012.

DEITOS, Maria Lucia de Souza. A Formação do profissional de Ciências Contábeis num contexto de permanente inovação dos processos produtivos. Revista Brasileira de Contabilidade. São Paulo, no 170, p 79-91 mar/abril 2008.

DOMINGUES, Gilmar Ferreira; SILVA, Manasses Antônio. Ética contábil: Um pensamento empresarial. Revista Inter Ação. Vol. 4, n. 1, jan./dez. 2007 - Paranaíba (MS): FIPAR Editora, 2007.

FORTES. José Carlos. Ética e responsabilidade profissional do contabilista. Fortaleza: Fortes, 2002.

GOMES, Karini de Freitas. A qualidade dos serviços contábeis como diferencial para seus clientes: um estudo em uma organização contábil de Criciúma - SC. Criciúma, 07 de Dezembro de 2011. Disponível em:<http://repositorio.unesc.net/handle/1/590>. Acesso 06 Out. de 2012.

MARTINELLI, Gilmar Mário. A Evolução Histórica e Noções Básicas de Contabilidade. 2002. Disponível em: <http://www.escritoriomartinelli.cnt.br/monografia.htm>. Acesso 08 Out. de 2012.

OLIVEIRA, Antônio Benedito Silva. CECCONELHO, Antônio Renato. BARBOSA, Claudionor Francisco. CÉLICE, Eduardo de Souza. KOUNROUZAN, Márcia Covaciuc. GIORGI Wanny Arantes Bogiovanni. Métodos e técnicas de pesquisa em contabilidade. São Paulo: Saraiva, 2003.

OLIVEIRA, Mariana Vieira de. O contador e suas conquistas profissionais: estudo comparativo dos recém-formados da Univali e Unisul, 2008, 71 p. (Curso de Ciências Contábeis)-Universidade Federal de Santa Catarina, Florianópolis, 2005.

PENNA, Gabriel. Seja o talento que o mercado procura. Você S/A, São Paulo, no 120, p 72-75, jun. 2008. 
Análise da visão dos acadêmicos concluintes do curso de ciências contábeis - UNEMAT campus de Tangará da Serra no ano de 2013/2, com relação ao curso e a expectativa de ingresso no mercado de trabalho.

Cristiane Deutschmann

Josiane Silva Costa dos Santos

Perfil Sócio e Econômico Tangará da Serra. 2011/ 12. Disponível em

<https://sites.google.com/a/unemat.br/perfil_tangara/economia $>$. Acesso 15 de Ago. de 2013.

PREIS, Bruna Regina da Silva et al. Ensino em contabilidade: uma análise do perfil dos estudantes do curso de ciências contábeis quanto à sua percepção do mercado de trabalho eo seu grau de capacitação. Cadernos da FUCAMP, v. 12, n. 16, 2013. Disponível em: < http://www.fucamp.edu.br/editora/index.php/cadernos/article/view/227 >. Acesso dia 22 de out. de 2013.

RIBEIRO, Jose Francisco Filho; LOPES, José; PEDERNEIRA, Marcleides. Estudando teoria da contabilidade, organizadores. São Paulo: Atlas, 2009.

RODRIGUES, Ana Kátia da Silva. O profissional contábil e as exigências do mercado de trabalho no município de Juína. 2009. Disponível em

<http://www.biblioteca.ajes.edu.br/arquivos/monografia_20110809162110.pdf>. Acesso 15 de Ago. de 2013.

SANTOS, Catarina Coelho. GALINDO, Silvia Rodrigues. 2007. Artigo (Pós-graduação) Universidade Salvador, Salvador, Bahia.

SÁ, Antônio Lopes de. Teoria da contabilidade. 3 ed. Atlas: São Paulo, 2002.

História Geral e das Doutrinas da Contabilidade. São Paulo, 2007.

A Evolução da Contabilidade. 2 ed. São Paulo: IOB, 2009.

Ética Profissional. 8. ed. 2. reimpr. São Paulo: Atlas, 2009.

Sauberlich, Karen Cristina Honório Cardoso. Fatores que produzem evasão acadêmica no curso de Ciências Contábeis da Unemat de Tangará da serra/MT. Revista Unemat de Contabilidade. Ed $1 \mathrm{n} 2$, Jul-dez/2012. Disponível em: <

https://sites.google.com/a/unemat.br/ruc/edicoes/v-1-n-2-jul-dez-2012> Acesso 10 de Set. de 2013.

SCARPIN, Maria Aparecida, and Wendel Conninck de Almeida. "Graduandos de Ciências Contábeis e sua carreira profissional." Revista de Estudos Contábeis 1.1 (2010): 24-37. Disponível em: <http://www.uel.br/revistas/uel/index.php/rec/article/view/9398>. Acesso 28 Ago. de 2013.

SILVA, Antônio Carlos Ribeiro da. MARTINS, Vilson Thomé Sardinha. História do pensamento contábil. $1^{\circ}$ ed. (ano 2996), 4 tir./Curitiba: Juruá, 2009.

SILVA, Antônio Carlos Ribeiro. Metodologia da pesquisa aplicada à contabilidade: orientação de estudos, projetos, artigos, relatórios, monografias dissertações, teses. 3. Ed. - São Paulo: Atlas, 2010. 
Análise da visão dos acadêmicos concluintes do curso de ciências contábeis - UNEMAT campus de Tangará da Serra no ano de 2013/2, com relação ao curso e a expectativa de ingresso no mercado de trabalho.

Cristiane Deutschmann

Josiane Silva Costa dos Santos

UNEMAT, Universidade do Estado de Mato Grosso. Departamento de Ciências Contábeis:

Sobre o Curso. Disponível em: 〈http://tangara.unemat.br/contabeis>. Acesso em 28 Ago. de 2013.

UNEMAT, Universidade do Estado de Mato Grosso. Disponível em:

<http://www.unemat.br/prppg/?link=detalhes_cursoLS\&detalhes_cursoLS=detalhes_cursoLS \&detalhes_cursoLS=51>. Acesso em 18 de Nov. de 2013. 